\title{
Investigational Study on Self Aeration Characteristic of Hydraulic Jump
}

\author{
A. Anandraj \\ Assistant Professor-IV, Dept. of Civil Engg. M.A.M Engineering College, Tamil Nadu, INDIA.
}

\begin{abstract}
Aeration by hydraulic jump is trouble-free and cost-effective way to achieve oxygen transfer than conventional oxygenation systems. The content of dissolved oxygen $(D O)$ in water helps to evaluate the quality of water. At jump, entrainment of air to water takes place due to difference in concentration causes oxygen molecules in the air to dissolve into the water. This paper describes the experimental investigation to aeration performance of hydraulic jump. In this study, self aeration performance of a classical hydraulic jump beyond a sluice gate has been experimented in a $0.15 \mathrm{~m}$ wide laboratory tilting flume. Experimental observation confirms that the positive linear relationship between aeration efficiency and energy loss along the jump.
\end{abstract}

Keywords: Aeration, hydraulic jump, dissolved oxygen.

\section{Introduction}

Hydraulic jump is an open channel phenomenon in which transition from supercritical to sub-critical flow occurs. It develops large-scale turbulence, surface waves and spray. Further it dissipates energy and ensures the entrainment of air into water. Jump is commonly created in the location where self aeration of flow is required in order to enhance the dissolved oxygen content of water/waste water in the treatment process. In addition for self aeration, hydraulic jump helps in mixing of chemicals in the treatment processes. It is also used on both artificial and natural channels to cut down velocity and prevent undue scour. Oxygen is essential for any living organism. Oxygen concentrations are much higher in air, which is about $21 \%$ oxygen, than in water, whereas in water its proportion is around $1 \%$. For survival of any aquatic organism, adequate oxygen is required in water. Where the air and water meet, this tremendous difference in concentration causes oxygen molecules in the air to dissolve into the water. More oxygen get dissolved into water when wind stirs the water or as the waves create more surface area and more oxygen diffusion can occur in water. Pollution of stream water due to mixing of sewerage water develops oxygen-demanding organic matter or nutrients that stimulate growth of organic matter and it decreases the average DO concentrations in water. Hence, the concentration DO in water is an important water quality indicator. Hydraulic jumps in the streams increase the amount of DO even though the water stays at short interval of time in the self aeration process. The same quantity of oxygen transfer would normally occur over several kilometers length in the stream. The main reason for this accelerated transfer is that air is entrained into the flow in the form of a large number of bubbles. These air bubbles in turn increase the surface area available for mass transfer. These air bubbles are entrapped by vortices with axes perpendicular to the flow direction. At the hydraulic jump, air bubbles are advected downstream into free shear layer characterized by intensive turbulence production before reaching the free-surface and finally escaping to the atmosphere. Air entrainment at hydraulic jumps is considered as one of the best means of air-water transfer of atmospheric gases such as oxygen and nitrogen. Several studies have been carried out to investigate the self aeration characteristic of hydraulic jumps. Generally, self aeration capability of hydraulic jump is expressed in terms of aeration efficiency. Holler (1971) correlated the aeration efficiency of a hydraulic jump with the velocity difference before and after the hydraulic jump. Avery and Novak (1978) formulated expression of efficiency of aeration at jump using upstream Froude number and Reynolds number in terms of unit discharge. Willhelms et al (1981) presented similar expression as that of Avery and Novak (1978). Kucukali and Cokgor (2007) developed a fuzzy logic model to predict hydraulic jump aeration efficiency based on experimental observations and measurements carried in the laboratory flume. Recently, Kucukali and Cokgor (2009) found that the hydraulic jump aeration efficiency has linear relationship with the energy dissipation rate for unit width of the channel. In this study self aeration performance of a hydraulic jump beyond a sluice gate has been investigated in classical $0.15 \mathrm{~m}$ wide laboratory tilting flume by varying channel slope as well as flow.

\section{Aeration Efficiency}

Self aeration is a natural phenomenon of transfer of oxygen from air towards the water across a free surface. The efficiency of aeration depends on the quantity of air intake at hydraulic jump. Gameson (1957) suggested an equation for finding aeration efficiency as follows 


$$
E=\frac{C_{d}-C_{u}}{C_{s}-C_{u}}
$$

Where $C_{d}-$ Concentration of dissolved oxygen in the upstream of hydraulic structure

$C_{u}$ - Concentration of dissolved oxygen in the downstream of hydraulic structure

$C_{s}-$ Saturated level of dissolved oxygen for a given ambient conditions.

Aeration efficiency of one indicates full transfer of oxygen in the water. Since the temperature plays a vital role in mass transfer mechanism, aeration efficiency needs to be converted based on standard temperature. Gulliver et al (1990) developed the relationship based on mass transfer similitude to adjust aeration efficiency to $20^{\circ} \mathrm{C}$ and denoted as $\mathrm{E}_{20}$.

$$
E_{20}=1-(1-E)^{\frac{1}{f}}
$$

Where $\mathrm{f}$ is an exponent

$$
f=1+0.02103(T-20)+8.261 \times 10^{-5}(T-20)^{2}
$$

Kucukali and Cokgor (2009) fitted the positive linear relationship between the aeration efficiency and energy dissipation rate as follows

$$
E_{20}=0.0015 \omega+0.01
$$

Where

$\omega$ - energy dissipation rate per unit channel width $(\mathrm{W} / \mathrm{m})=q x \Delta H x \gamma$

$\mathrm{q}$ - flow `rate per unit channel width $\left(\mathrm{m}^{3} / \mathrm{s} / \mathrm{m}\right)$

$\gamma$ - specific weight of water $\left(\mathrm{N} / \mathrm{m}^{3}\right)$

$\Delta \mathrm{H}$ - head loss along the hydraulic jump

$$
\Delta H=\left(y_{1}+\frac{v_{1}^{2}}{2 g}\right)-\left(y_{2}+\frac{v_{2}^{2}}{2 g}\right)
$$

$\mathrm{y}_{1}$ - flow depth before the jump (m)

$\mathrm{y}_{2}$ - flow depth after the jump (m)

$\mathrm{v}_{1}$ - velocity of flow before jump $(\mathrm{m} / \mathrm{s})$

$\mathrm{v}_{2}-$ velocity of flow after jump $(\mathrm{m} / \mathrm{s})$

$\mathrm{g}$ - acceleration due to gravity $\left(\mathrm{m}^{2} / \mathrm{s}\right)$

Holler (1971) correlated the aeration efficiency of a hydraulic jump with the velocity difference before and after hydraulic jump

$$
E_{20}=1-\frac{1}{1+0.0463 \Delta v^{2}}
$$

Where $\Delta \mathrm{v}=\mathrm{v}_{1}-\mathrm{v}_{2}$

\section{Experimental Setup}

Experiments are conducted in $4 \mathrm{~m}$ length hydraulic tilting flume. The flume consists of a long channel with transparent side walls. Water from the supply pump is supplied to the flume inlet section through a gate valve and a flexible hose. This water after passing through the stabilization zone, flows in the transparent test section and returns to the sump tank. Discharge was measured using orifice meter provided at the inlet pipe. The height of the water level both in upstream and downstream of the jump is measured using pointer gauge. Flow rate is controlled by a valve available next to the pump and slope of the channel was adjusted using hand operated screw mechanism in order to get different range of Froude numbers. Hydraulic jumps are formed both by controlling flow as well as setting different slopes. The scale available along with the see-through side wall is 
used for measurement of roller lengths. DO is measured simultaneously both in upstream side and also in downstream side using hand held DO 6 meter. Temperature measurement is also available in degree Celsius. By altering bed slope of the channel and also varying the flow rate, nineteen hydraulic and quality data are generated from the setup. Figure 1 shows the picture of air entrainment at the hydraulic jump.

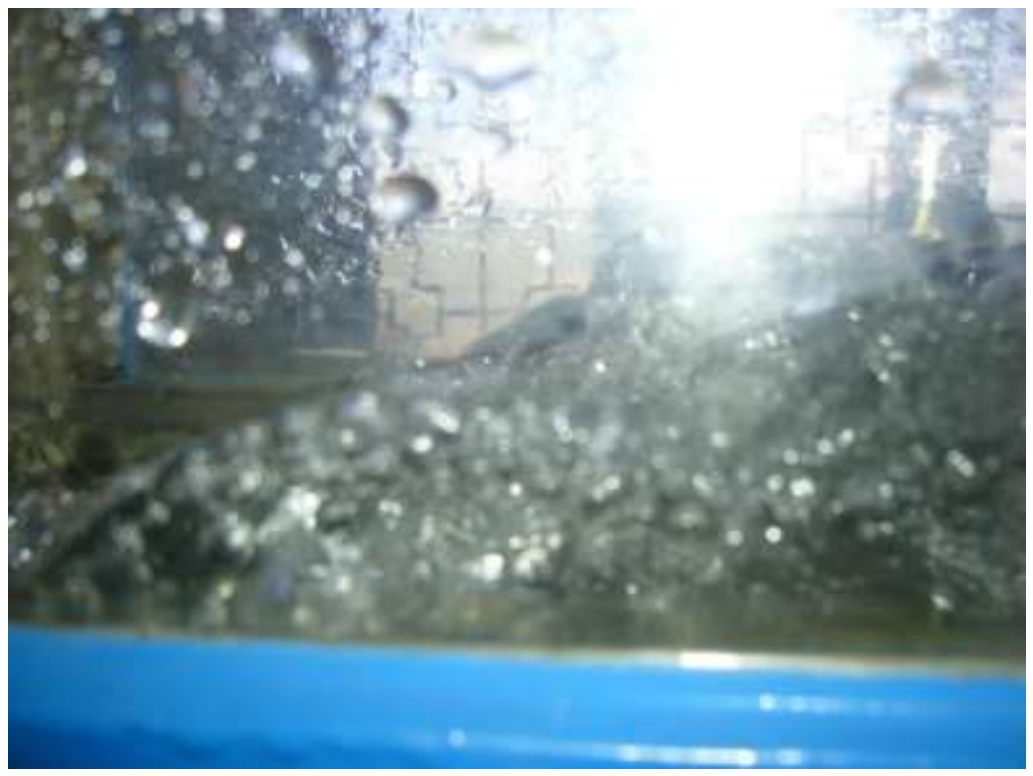

Fig. 1 Air entrainment at hydraulic jump

\section{Result And Discussion}

In the experiment, the bed slope and flow is adjusted until more foam is visualized. Room temperature is measured at several interval of time during aeration measurements and it is found as $28^{\circ} \mathrm{C}$ and it is almost constant during measurement time. Table 1 shows the hydraulic data obtained from the experiments for hydraulic jump. Table 2 shows the dissolved oxygen level before and after formation of jump.

Table 1 Hydraulic particulars of the hydraulic jump

\begin{tabular}{|c|c|c|c|c|c|c|c|c|}
\hline $\begin{array}{c}\text { Sl. } \\
\text { No. }\end{array}$ & $\begin{array}{c}\mathrm{y}_{1} \\
(\mathrm{~cm})\end{array}$ & $\begin{array}{c}\mathrm{y}_{2} \\
(\mathrm{~cm})\end{array}$ & $\begin{array}{c}\mathrm{Q} \\
\left(\mathrm{m}^{3} / \mathrm{s}\right)\end{array}$ & $\mathrm{v}_{1}$ & $\mathrm{v}_{2}$ & $\Delta \mathrm{H}$ & $\mathrm{Fr}_{1}$ & $\mathrm{Fr}_{2}$ \\
\hline 1 & 44.5 & 7.5 & 0.0051 & 1.3214 & 0.4422 & 0.0281 & 2.6367 & 0.5104 \\
\hline 2 & 42.5 & 9.5 & 0.0048 & 1.2627 & 0.4317 & 0.0231 & 2.5346 & 0.5067 \\
\hline 3 & 39.5 & 12 & 0.0044 & 1.3256 & 0.4079 & 0.0316 & 2.8534 & 0.4870 \\
\hline 4 & 38.5 & 13 & 0.0042 & 1.3246 & 0.4041 & 0.0328 & 2.9046 & 0.4894 \\
\hline 5 & 36 & 11.25 & 0.0041 & 1.2989 & 0.4129 & 0.0316 & 2.8415 & 0.5093 \\
\hline 6 & 32.5 & 10.25 & 0.0039 & 1.2201 & 0.4036 & 0.0241 & 2.6567 & 0.5054 \\
\hline 7 & 40 & 12 & 0.0044 & 1.4354 & 0.4649 & 0.0512 & 3.2009 & 0.5899 \\
\hline 8 & 40 & 12 & 0.0044 & 1.4216 & 0.4988 & 0.0520 & 3.1546 & 0.6556 \\
\hline 9 & 40 & 12 & 0.0044 & 1.3079 & 0.4527 & 0.0342 & 2.7838 & 0.5669 \\
\hline 10 & 40 & 12 & 0.0044 & 1.2011 & 0.4527 & 0.0226 & 2.4500 & 0.5669 \\
\hline 11 & 28.5 & 25.4 & 0.0015 & 1.1519 & 0.1847 & 0.0214 & 3.9891 & 0.2562 \\
\hline 12 & 29.8 & 21.8 & 0.0024 & 1.1651 & 0.2439 & 0.0152 & 3.2016 & 0.3066 \\
\hline 13 & 31.2 & 22.2 & 0.0025 & 1.3903 & 0.2691 & 0.0448 & 4.0521 & 0.3450 \\
\hline 14 & 34 & 18 & 0.0033 & 1.3903 & 0.3320 & 0.0419 & 3.5092 & 0.4095 \\
\hline 15 & 38 & 13.5 & 0.0041 & 1.3763 & 0.3258 & 0.0266 & 3.1072 & 0.3578 \\
\hline 16 & 41 & 10.7 & 0.0046 & 1.3605 & 0.3559 & 0.0244 & 2.8958 & 0.3875 \\
\hline 17 & 42.5 & 9.3 & 0.0048 & 1.4241 & 0.3726 & 0.0328 & 3.0313 & 0.4056 \\
\hline 18 & 43.5 & 7 & 0.0050 & 1.5272 & 0.4024 & 0.0491 & 3.2873 & 0.4446 \\
\hline 19 & 44 & 8 & 0.0050 & 1.3903 & 0.3531 & 0.0217 & 2.8652 & 0.3667 \\
\hline
\end{tabular}


Table 2 Dissolved Oxygen level before and after the hydraulic jump

\begin{tabular}{|c|c|c|c|c|c|r|}
\hline $\begin{array}{c}\text { Sl. } \\
\text { No. }\end{array}$ & $\begin{array}{c}\mathrm{C}_{\mathrm{u}} \\
\mathrm{mg} / \mathrm{l}\end{array}$ & $\begin{array}{c}\mathrm{C}_{\mathrm{d}} \\
\mathrm{mg} / \mathrm{l}\end{array}$ & $\begin{array}{c}\mathrm{C}_{\mathrm{s}} \\
\mathrm{mg} / \mathrm{l}\end{array}$ & $\mathrm{E}$ & $\mathrm{E}_{20}$ & $\begin{array}{c}\omega \\
\text { Watts/m }\end{array}$ \\
\hline 1 & 6.2800 & 6.3600 & 8.0900 & 0.0442 & 0.0461 & 9.3332 \\
\hline 2 & 6.4800 & 6.5900 & 8.0900 & 0.0683 & 0.0712 & 7.2284 \\
\hline 3 & 6.4200 & 6.5400 & 8.0900 & 0.0719 & 0.0749 & 9.0348 \\
\hline 4 & 6.3800 & 6.4600 & 8.0900 & 0.0468 & 0.0488 & 9.0389 \\
\hline 5 & 6.4400 & 6.5800 & 8.0900 & 0.0848 & 0.0884 & 8.5759 \\
\hline 6 & 6.5600 & 6.6700 & 8.0900 & 0.0719 & 0.0749 & 6.1941 \\
\hline 7 & 6.1600 & 6.2400 & 8.0900 & 0.0415 & 0.0375 & 14.7513 \\
\hline 8 & 6.3800 & 6.4800 & 8.0900 & 0.0585 & 0.0530 & 15.1843 \\
\hline 9 & 6.5900 & 6.6600 & 8.0900 & 0.0467 & 0.0423 & 9.8727 \\
\hline 10 & 6.4200 & 6.5600 & 8.0900 & 0.0838 & 0.0760 & 6.8993 \\
\hline 11 & 5.6700 & 5.8100 & 8.0900 & 0.0579 & 0.0524 & 2.0548 \\
\hline 12 & 5.8100 & 6.0100 & 8.0900 & 0.0877 & 0.0796 & 2.3392 \\
\hline 13 & 6.3400 & 6.5200 & 8.0900 & 0.1029 & 0.0934 & 7.3362 \\
\hline 14 & 5.6400 & 5.8900 & 8.0900 & 0.1020 & 0.0926 & 9.1428 \\
\hline 15 & 5.7800 & 6.0300 & 8.0900 & 0.1082 & 0.0983 & 7.1927 \\
\hline 16 & 5.8000 & 6.0300 & 8.0900 & 0.1004 & 0.0912 & 7.3224 \\
\hline 17 & 5.7600 & 6.0100 & 8.0900 & 0.1073 & 0.0974 & 10.3088 \\
\hline 18 & 6.3200 & 6.5100 & 8.0900 & 0.1073 & 0.0975 & 16.1890 \\
\hline 19 & 6.0800 & 6.2800 & 8.0900 & 0.0995 & 0.0903 & 7.0903 \\
\hline
\end{tabular}

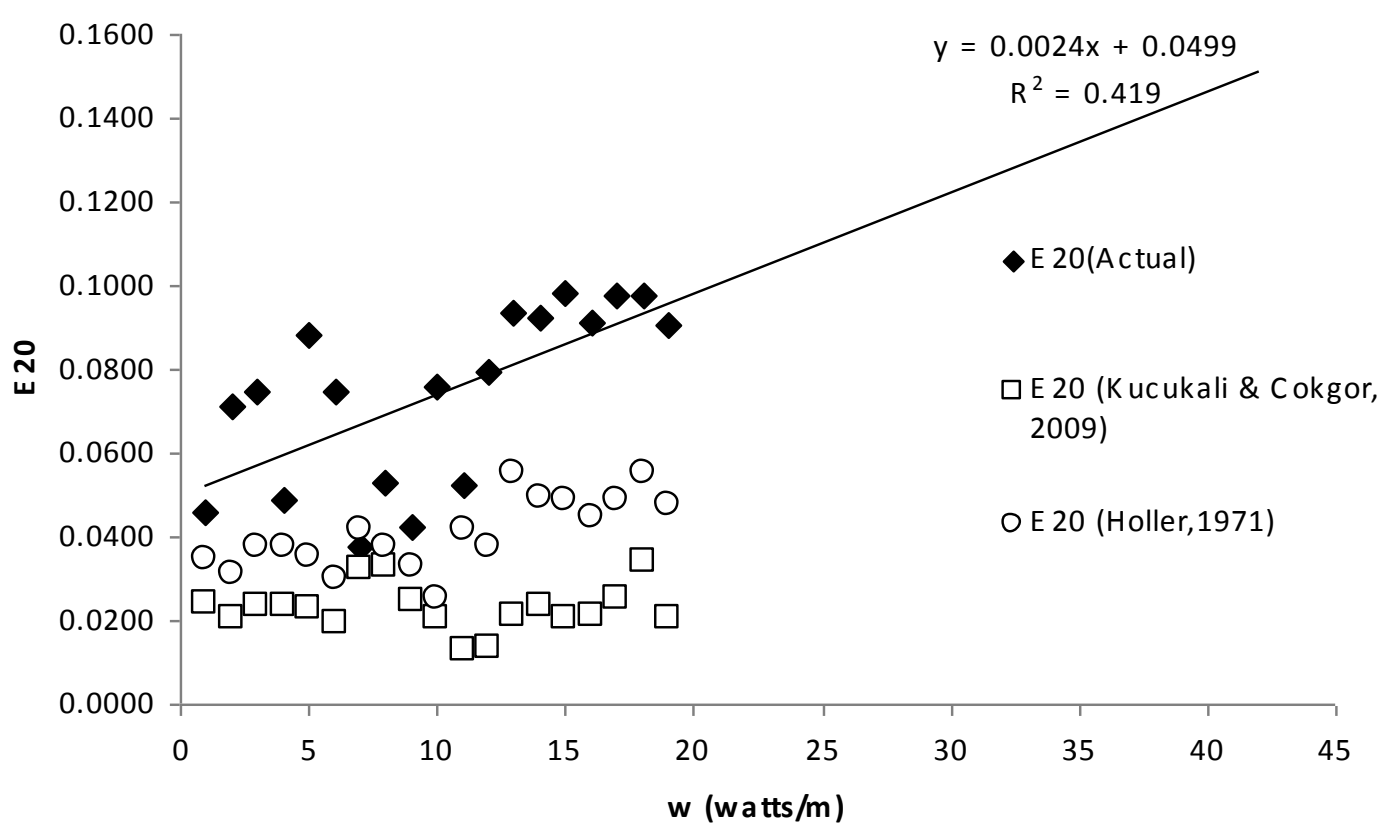

Fig.2 Aeration Efficiency $E_{20}$ as a function of energy loss

The Froude number varies from 2.5 to 4.0 before jump and corresponding velocity of flow varies between $1.15 \mathrm{~m} / \mathrm{s}$ to $1.52 \mathrm{~m} / \mathrm{s}$. The downstream side Froude number is calculated and it falls in the range of 0.25 to 0.5 and corresponding velocities are $0.18 \mathrm{~m} / \mathrm{s}$ to $0.5 \mathrm{~m} / \mathrm{s}$. Water temperature at the time of experiment is measured and it is found as $22^{\circ}$. The actual aeration efficiency is calculated using expression 1 . This actual aeration efficiency is converted to the standard temperature using equations 2 and 3. Also the aeration efficiency is found out according to the expression presented by Kucukali and Cokgor (2009) and Hiller (1971) for comparison. A graph is plotted between $E_{20}$ and energy loss along the jump and is presented in Figure 2. The available experimental set up could create the maximum of $20 \mathrm{Watts} / \mathrm{m}$ of energy loss. It can be seen from the plot that the present experiment result shows the higher aeration efficiency than predicted value based on expression 4 and 6. A linear trend is fitted using actual data and it is shown in the plot that the positive linear 
relationship between the aeration efficiency and energy dissipation rate. The low $\mathrm{R}^{2}$ value is obtained for the set of data.

$$
E_{20}=0.0024 \omega+0.0499
$$

As pointed out by Kucukali and Cokgor (2009), aeration efficiency increases with the increase of energy loss along the jump. The deviation in the co-efficient of $E_{20}$ expression resulted in the proposed expression to that of Kucukali and Cokgor (2009) should be due to the quality of the water used and its initial value of DO contents. Further, there is almost parallel shift of actual data point with that of other two cases. It is evident that the saturation value of DO and initial DO value of water have influence in aeration process.

\section{Conclusion}

This experimental work confirms that the existence of positive relation between the aeration efficiency and energy loss along the jump. Aeration efficiency increases in proportion with the increase in energy loss as stated in the literature. The deviation resulted with predicted values show that the initial DO content of water and other quality parameter of water should have some influence in the self aeration process in the jump. Hence it is essential to carry out vast experimentations with different quality of water to identify other influencing parameters to ensure the self aeration process at hydraulic jump.

\section{Reference}

[1] Holler, A. G. (1971). The mechanism describing oxygen transfer from the atmosphere to discharge through hydraulic structures. Proc., $14^{\text {th }}$ IAHR Congress and Conf., Paris, France, 372-382.

[2] Avery and Novak (1978). Oxygen transfer at hydraulic structures. Journal of hydraulic engineering, ASCE, 104(11), 1521-1540.

[3] Willhelms, S.C., Clark, L., Wallace, J.R., and Smith, D.R., (1981). Gas transfer in hydraulic jumps. Technical Report E-81-10, US Army Engineer Waterways Experiment Station, CE, Vicksburg Miss., USA.

[4] Kucukali, S. and Cokgor, S. (2007). Fuzzy logic model to predict hydraulic jump aeration efficiency. Journal of Water Management, 160(4), 225-231.

[5] Kucukali, S. and Cokgor, S. (2009). Energy concept for predicting hydraulic jump aeration efficiency, Journal of Environmental Engineering, ASCE, 135(2), 105-107.

[6] Gulliver, J.S., Thene, J.R., and Rindels, A.J. (1990). Indexing gas transfer in self-aerated flows. Journal of Environmental Engineering, ASCE, 116(3), 503-523.

[7] Gameson, A.I.H. (1957). Weirs and aeration of rivers. Journal of institution of water engineers, 11(5), 477-490. 